\title{
SHAPE AND CONSTRUCTION OF BRICK VAULTS. CRITERIA, METHODS AND TOOLS FOR A POSSIBLE CATALOGUE
}

\author{
R. Brumana ${ }^{a}$, P. Condoleo ${ }^{\text {b, } *}$, A. Grimoldi ${ }^{\text {c }}$, A. G. Landi ${ }^{\text {c }}$ \\ ${ }^{a}$ Dept. of Architecture, Built Environment and Construction Engineering, Politecnico di Milano, Milan, Italy - \\ raffaella.brumana@polimi.it \\ ${ }^{\mathrm{b}}$ Dept. of Civil and Environmental Engineering, Politecnico di Milano, Milan, Italy - paola.condoleo@polimi.it \\ ${ }^{\mathrm{c}}$ Dept. of Architecture and Urban Studies Politecnico di Milano, Milan, Italy - (alberto.grimoldi, angelogiuseppe.landi) @polimi.it
}

KEY WORDS: built heritage, cloister vaults, laser scanning, photogrammetry, thermographic investigations

\begin{abstract}
:
The use of cloister vaults in the construction of noble buildings, as covering elements for square or rectangular rooms, is widespread and well-known. The geometric continuity at the intrados makes generally possible the execution all over the span of frescoes, stucco and decorations. The construction of brick vaults, from the late Middle Age, was sped up by limiting the centering to the wooden planks arches that were instrumental in the profile determination. Nowadays, the availability of several procedures, phases and tools for carrying out a survey allows to draw reliable assumptions about the construction methods and the execution time. It is mandatory to determine the properties of the binders, the shape and dimensions of the bricks, and to carry out a comparison between the geometry of the intrados surface and the evidences emerging at the extrados. The support of the laser scanner technique allows to accurately identify the surface profile and thickness. All these indications, in turn, are useful, in view of an interpretation of the structural behavior, to identify weaknesses, and to highlight contributing factors of instability (if any).

The paper focuses on a well-documented case, the Magio Grasselli palace in Cremona in which the cloister vaults of two main rooms show different construction systems, although they were built almost at the same time. The thermographic recordings and laser-scanner surveys highlight the various arrangements used for the cloister vaults.
\end{abstract}

\section{INTRODUCTION}

\subsection{Studies on the vaults and a synthetic overview of the European perspective}

Considering their importance both architectural and figurative, the construction of vaults is an ever-current theme in European culture, though the intensity and orientation thereof may differ in the various linguistic ambits.

In France, thanks to the policy set up by Jean Marie Pérouse de Montclos, the revival of the inventory in 1964 led to a census in the significant realisations of stereotomy and the re-evaluation of the vast and learned writing treatises on the subject from the XVI to the XIX centuries (Pérouse de Montclos, 1982). The "vocabulaire" of architecture reconnects the typology with the lexicon through the graphic and photographic illustration of individual examples (Pérouse de Montclos, 1972), but this terminological correspondence is possible insofar as the central administration and its culture have in a certain way "standardised" language. In Spain, studies carried out are less systematic and more recent, but they have renewed substantially the history of architecture focussing on - in the late Gothic period and in Renaissance construction (Palacios, 1989) - the quality of stereotomic construction. In England, as in France, from the first quarter of the $19^{\text {th }}$ century (Willis, 1813) the classification of vaulted systems represented an essential moment in the re-evaluation of medieval construction, but the scarce diffusion of real vaults in the construction of the Modern Age has circumscribed the theme to its most monumental and ancient heritage, which is relatively scarce. In Germany, on the other hand, from the Middle Ages to the Baroque period and throughout the $19^{\text {th }}$ century, stone vaults, and moreover brick vaults, were very common and the technical literature and drawings increase steadily right up to the Modern Age (Wieland, 2008). It is no surprise, therefore, to see the sheer number and quality of the studies and presence of yearbooks (Erhalten historisch bedeutsamer Bauwerke) in which even experimental archaeology has played an important role (Wieland, 2012). Studying the individual examples in great depth, we can see that they are often strongly representative of a heritage that is well documented by exhaustive inventories drawn up from the beginning of the $20^{\text {th }}$ century.

The Italian treatises - with the significant exception of Guarini - is often elementary and repetitive. From the mid- $17^{\text {th }}$ century, direct reference is made to the French texts (Forni, 1993). Contemporary studies therefore lack an overview of reference leading inevitably to an involuntary localism - see the "Manuali del recupero" of the individual cities - but also in more extensive works the "geographical" skills of the authors appear to determine the ambit of treatment and the time-space perimeter within which they are studied.

Brick vaults in Northern Italy between the $16^{\text {th }}$ and $18^{\text {th }}$ centuries are characterised by a wide variety of types and constructive solutions: much more diverse arrangements (apparecchiatura in Italian), such as in stereotomy, may correspond to the same shape, though elementary - a cloister vault, a groined vault, a pendentive dome. The use of brick, however, also changes the geometry: the difference is not immediately visible, but digital survey techniques quickly highlight it. The arrangement - no less than shape and dimensions - marks the static behavior of the vaults, as recently underlined by Richard A. Etlin (2015).

It is difficult to reconstruct regional specifics: Piedmont stands out for the vast quantity of complex examples and for their

* Corresponding author 
success in historiography, way beyond their mere singularity (Piccoli, 1999 and Piccoli, 2001). Evolution through time can also only be found in the details, or in the lower frequency of one or another typology. The very same sub-Alpine master builders exported unique typologies - such as framed arches vaults - from Abruzzo (Varagnoli, 2007) to Bohemia. When brick is used we find rational methods of construction that spread throughout Europe as evident in the drawings of German handbooks from the late $18^{\text {th }}$ and early $19^{\text {th }}$ centuries dedicated to the texture of the vaults (Gilly 1797). Stefan M. Holzer (2013) has succeeded in tracing an overview that not only deals with Italian case studies but also pairs them with similar German examples. Viollet-le-Duc, under Construction in the fourth volume of the Dictionnaire, (first edition of the first volumes: 1854-57), considered groined vaults as characteristic of medieval English construction, in which the ashlars were laid perpendicularly to the diagonal arches. The system is, however, extremely widespread throughout the Modern Age in the brickmanufacturing regions of continental Europe: Holzer illustrates one example - among the many - in Augsburg but there are many cases also south of the Alps. There are two series of them from the second half of the $17^{\text {th }}$ century in the Cremona building subject to this article (we don't move far...) (Figure 1).

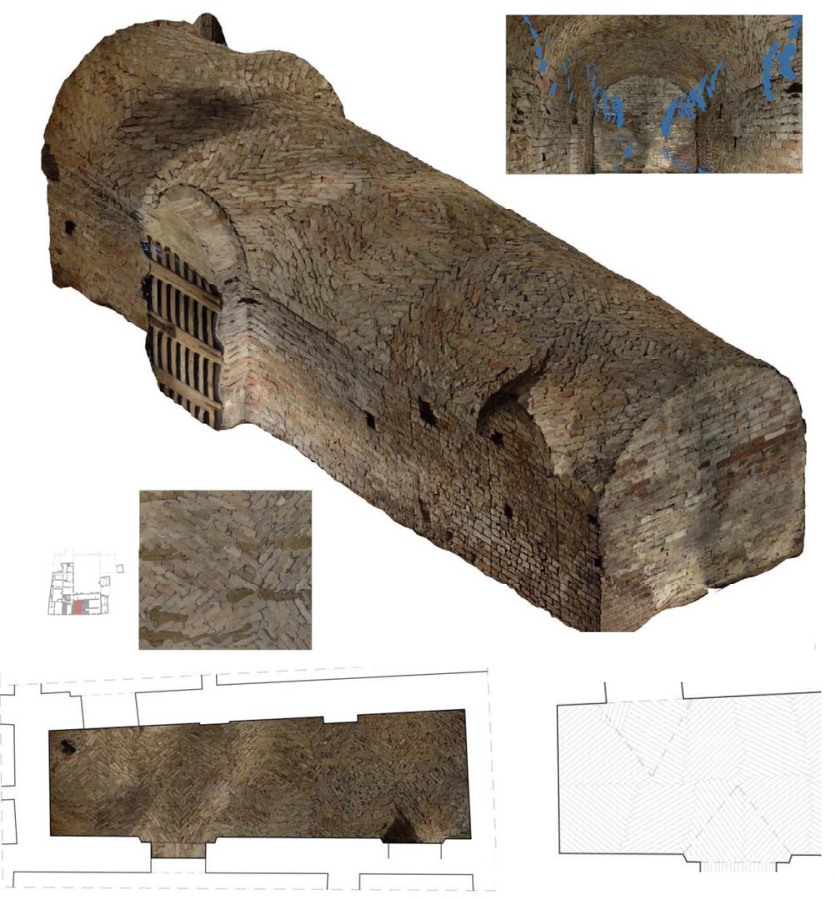

Figure 1. Magio Grasselli palace in Cremona: groined vaults in which the bricks were laid perpendicularly to the diagonal arches

Texts on stereotomy suggest that the most difficult solutions were implemented throughout Europe in permeating complex solids. Guarini's Euclides adauctus appears a widely shared reference, more than the treatise on architecture published in 1737. In this way the framework could be over-simplified, reduced to its bare bone consisting of centerings that corresponded to the profile of the arches, and the bricks were then laid by hand in subsequent arches that could be quickly completed. In general, the bricks are soldier-laid; rarely do we find thicker arches, and while there are many light vaults, the bricks are laid in folio. The main curvatures are often indicated by thicker arches, from one to two bricks thick. These also act as reinforcement or permitted the phases of construction to be carried out in order. They are often coordinated with the wallribs (the so-called Italian frenelli) and with the extrados tie rods to reduce the side thrust and maintain verticality of the side walls during the slow setting of lime mortar.

The widespread use of plastered masonry hides the arrangement that is otherwise visible in cut-stone vaults. The extrados cannot be seen when they are supporting a floor above. In this, the extensive use of thermography is vital. They are just as many obstacles, but they may become an advantage insofar that the most modern survey techniques integrating a variety of instruments may find herein a significant moment of experimentation. Determining the (at times extremely complex) geometry of the vaults was an essential phase of construction (Oreni et al., 2013). Ensuring the stability of the springers, the shape, both that of the overall structure as well as that of the arrangement, and also that of the ashlars, is essential to guaranteeing the static equilibrium. French stereotomy represents the most extended and coherent development of this know-how. The treatise writing is known and, in different ways and measures, according to the local conditions, applied throughout Europe in the $17^{\text {th }}$ and $18^{\text {th }}$ centuries. A fundamental part of the interpretation is precise inspection but this should be continually correlated to the constructive methods, the laying of the stones or bricks, and orientates both the collection of the data as well as their rendering.

\subsection{From the lesson of 'repertoires' toward HBIM vault libraries: an updatable geographic catalogue}

The patient reconstruction of the geometry and construction techniques allowed to understand the constructive richness, made of recurrent elements and specific features, sketching a mixed pattern of workers and constructive knowledge.

This process may result into current geographical updatable abaci, inheriting the tradition of the French repertoires that can be nowadays supported by HBIM: the BIM modelling process could lead to BIM libraries of vaulted elements that should be, however, not aimed at flattening and oversimplifying these valuable items to a unique parametric matrix for "copy-andpaste" operations at will, with mere changes of dimensions. Unfortunately, an oversimplification of complex elements (such as vaults) is often the rule in the application of BIM to the cultural heritage. This oversimplification is the demonstration of incomplete knowledge and deviate interpretation of BIM that could be used, on the contrary, to better handle differences and peculiarities (Volks, 2014; Fai, 2013). Protocols approach handling with the complexity of the architectural heritage and its components are working in this direction (AEC, 2014; AIA, 2015; NBS, 2016).

Through the concept itself of BIM instances the families of the vaulted elements are enriched by the richness of unique and complex elements, assigning to each object the added value of the multiplicity, "hic et nunc". What is different is the point of view that should be aimed not at unifying, but at the comprehension of the acquired knowledge. As testified by some recent experiences (Barazzetti et al., 2015a), BIM models support this different approach to complex surfaces modeling and NURBS (Piegl, 1997; Banfi, 2016).

The availability of a detailed three-dimensional model allows a backward knowledge of the construction technique, maybe not in its entirety, but sufficient enough to explain and highlight that the provision and use of centering in the constructive phase, as previously mentioned, "changes" the geometric shape by creating multiple variations. 
This information could be a useful means to improve the understanding of the structural behavior of vaults. Although the new modelling strategies allow to introduce the types of vaults and the materials in the numerical models, in comparison to the past, often an oversimplification of the structure remains, which can lead to an incomplete understanding of the structural behaviour. In Italy, the national standard helps by emphasizing the importance of taking into account the historical knowledge of the building, the construction techniques and, among other things, the state of damage, when setting up a numerical model. Considering the case of vaults, in particular, the structural behaviour can be adequately captured through a suitable reduction to its generator arc. Moreover, the analysis of the three-dimensional geometry of the structure should be aimed at identifying possible symmetries, in order to bring in further simplifications. International debates on the $\mathrm{LoD} / \mathrm{LoA} / \mathrm{LoI}$ (Level of Detail, of Accuracy and of Information) approach to BIM when applied to existing and complex building heritage (Fai, 2014) are witnessing the maturity of the thematic and complexity issue: they are progressively moving the attention from the LoD linear sequence 'from simple to complex' (i.e LoD100, 200, 400) traditionally applied to the new and simple building through the different design steps, from the preliminary study to the executive design, to a 'mixed open approach' taking in account the understanding process asking to anticipate the complexity of the morphology and related behaviour since the first preliminary stages (Barazzetti, 2016). Considering the continuous updating of commercial software for the numerical model during the last years, it would be interesting to systematically introduce the available integrated information in BIM (understood as written above), in order to obtain results that are able to take into account the multi-faceted constructive complexity of real structures (Barazzetti, 2015b).

\section{A CASE OF 'CLOISTER' VAULTS: AMONG SHAPES AND CONSTRUCTION TECHNIQUE}

The case study selected to illustrate the described methodology is the Magio Grasselli palace in Cremona, since it presents a multi-facet variety of apparently similar vaults, in facts characterized by different construction systems. Particularly here are shown two main rooms that present a shape that can be traced back to the common generic classification of 'cloister vaults' but realized with 2 different geometric arrangements systems, one with the typical semicilindric intersection of 2 barrel vaults (2 development surfaces with a simple curvature), one with a double curvature surface obtained with the arrangements of the tiles, thus more similar to a dome system. The final 'visible' effect is a cloister vault but the geometric roles are indeed very different.

The documentary research on Magio Grasselli palace (Landi, 2011) has established the sequence of the constructive phases of the building. By correlating the archive data with surveys and diagnostic investigations we have been able to date the vaults. Without necessarily sinking into technological determinism or mechanical processes of chrono-typological dating, this limited but reliable evidence allows for better understanding of the more general processes to constructively refine brick vaults in a medium size city, however attentive to receiving technological updating and ready to export innovative solutions. The most complex vaulted passageway and the contemporary presence of different constructive outlines could be clearly witnessed in Palazzo Magio Grasselli between 1760 and 1785. In the more general citizen overview, evolution is divided into longer times, and is affected by multiple social, economic and cultural factors that determine the choice of clients, architects and master builders. The in-depth studies undertaken on Palazzo Pallavicino Soldi and Palazzo Raimondi Stauffer, whose dating, with the exception of the famous façade, is different from what reported in existing literature (Visioli, 2001), demonstrated the longue durée of some constructive techniques, which were first implemented in the XVI century and still in use during the first few decades of the XIX century.

The Magio Grasselli palace (Figure 2), where late medieval buildings were partially dismantled and transformed into a modern aristocratic palace, was designed by architect Francesco Pescaroli from 1658 until 1681, the year Camillo Magio - client and amateur architect - died: construction was interrupted and, in 1703, a post mortem inventory describes a series of noble apartments which were only completed in the main body overlooking the road. The anti-chamber room n. 3.27 (for the numbering room see Figure 2) is rustic in style, with rough plastered walls, a wooden intermediate floor and a roof. Only around 1760 did Camillo II Magio and his wife Teresa Crivelli resume construction of the interior wing, partly demolishing and partly raising existing buildings. This partially determined the distribution of the rooms and we can still see the structural joints between the old and the new. The materials resulting from demolition were partially reused as we can see from the re-adapted wooden ceilings as were probably the bricks of the walls and the vaults, cleaned of the earthen bed-fixing mortars. Between 1768 and 1775 all these rooms were covered with cloister vaults, and the main hall was decorated by the painter Giovanni Manfredini (Figure 3) as we can see by the writing "JM 1772". By 1780, work was completed by Marquis Giuseppe Magio, son of Camillo II: the Magio-Araldi coats of arms allow us to date Manfredini's decoration to around 1780, the year Giuseppe Magio married Ippolita Araldi.

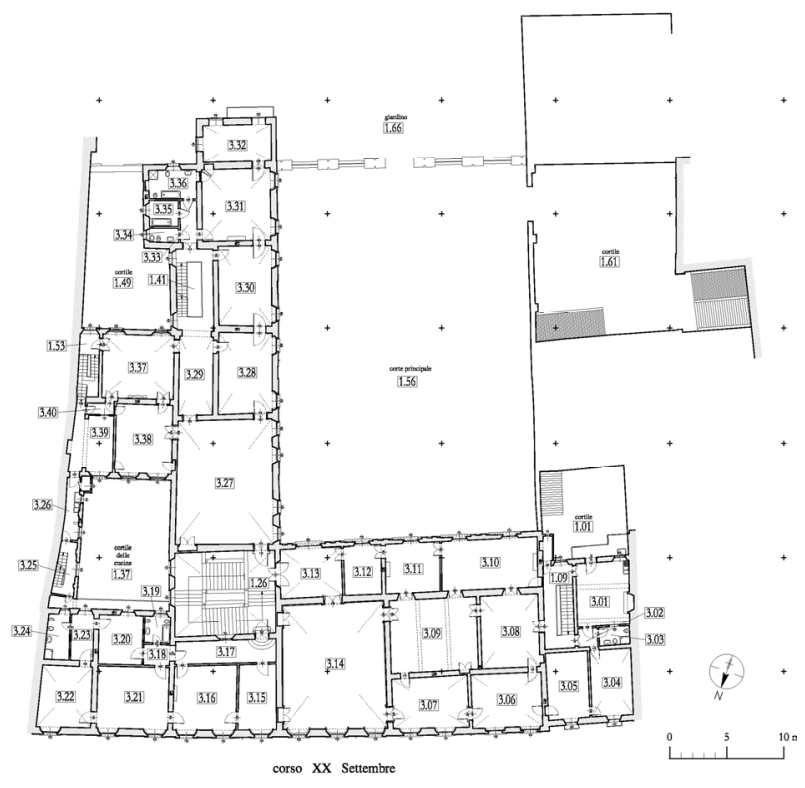

Figure 2. Plan of piano nobile with room numbering.

On the piano nobile overlooking the road to the east of the entrance, the wooden ceilings of the apartment and the antichamber hall were replaced by cloister vaults as we can see by a number of traces in the attics and above the false ceilings: the documents do not clarify if the vaults date back to the work undertaken by Giuseppe Magio around 1785 - the year in which Manfredini signed the decoration of the anti-chamber hall [3.14] - or whether they were the result of a previous intervention no earlier than mid-century, as Natali decorated the 
apartment to the west, with wooden ceilings, between 1713 and 1724 (Figure 4).

The archival, metric and thermographic information concerning the Magio Grasselli palace are abundant and considerable, and are integrated with the plurality of data, essential to define an elevated standard of documentation, which allows to justify both detailed hypotheses on the construction techniques, and classification criteria. It is important, however, to subject the whole to a critical examination, in order to define principles effectively shared and aimed at building a reference system, whose absence was already pointed out.

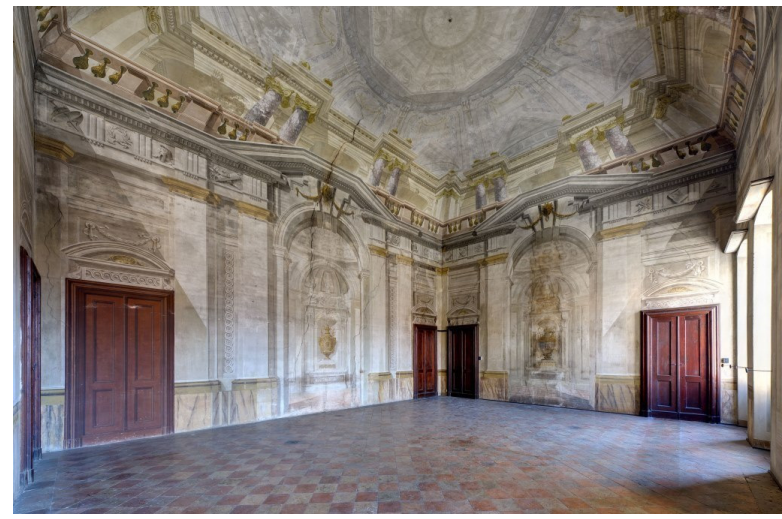

Figure 3. Magio Grasselli palace in Cremona, the room 3.27 painted by Giovanni Manfredini (photo by Giuliano Regis).



Figure 4. Magio Grasselli palace in Cremona, the room 3.14 painted by Giovanni Manfredini (photo by Giuliano Regis).

In order to understand the similarities and differences, the construction techniques and the state of damage of the halls vaults, an integrated survey using laser scanning, photogrammetry and thermographic investigations was carried out. Such a survey allowed understanding the vault morphology and the masonry pattern, highlighting certain critical aspects of the structural elements, the kind of instability and decay, and the mechanisms (Brumana et al., 2014). The thermographic recordings and laser-scanner surveys highlight the various arrangements used for the cloister vaults (Figure 5).

In the rooms of the subsequent enfilade [3.28, 3.30 and 3.31] on the other hand, the vaults run parallel to the wall, in variable heights, in correspondence with the lowest radius of the curve (and the highest slope) of the polycentric arch that makes up the section. In the lowered central area the bricks are laid diagonally to form two contrasting herringbones, with a rotation of the direction that resembles, in simplified way, the "böhmischen Kappen". The extrados are hidden by flooring but we can make out the presence of metallic tie rods with struts to contrast the side thrust, laid at the same time as the side walls and the vaults themselves. The last room towards the garden also has a cloister vault, the heads of which are formed by bricks in diagonal courses to form a sort of cuff, while in the centre the weft runs parallel to the springers. Dimensions are limited: the main body of the building of which it is part is a later addition.

The rooms in the apartment overlooking the road [3.15-3.17] $\mathrm{e}$ [3.18-3.21] have the same constructive characteristics as those of the large room overlooking the road [3.14] where the bracing arches, visible from the extrados, were the centring outline of the vault's profile and enabled it to be built without the support of planks. The extrados arches vary in width from one to two bricks thick in the vaults of the smaller rooms and tie rods with struts and web-ribs are located in correspondence with this ribbing.

In the main hall, the four arches crossing perpendicularly to the walls on which the vault is built are two bricks wide and protrude half a brick above the extrados as ribbing, while the intrados contains a more complex construction. This is visible in thermography only in the keystones where they cross over marking out the central bay: here we can see parallel courses of brick-on-soldier. At the springer are double header bricks alternating with in folio bricks that connect the arches to a continual leaf again in folio brick parallel to the springers, which also bend horizontally in quarter-circles in correspondence with the corners, resulting in a kind of cone shape: this solution, in which the arrangement is regular while the geometry is uncertain, allows the realisation of an intrados with no corners, perfect for uninterrupted decoration, mediating with the quadrangular plan of the main halls. The thickness of the bays - measured in correspondence with the holes for the lamps and verified instrumentally - never exceeds $10 \mathrm{~cm}$, including the topping and plaster.

More in detail, the three-dimensional model of the intrados of the hall of Manfredini [3.14] at the first floor, over the porch, obtained from the laser scanner clouds, has been integrated with the three dimensional model of the masonry pattern, visible from the extrados, obtained from an elaboration of photogrammetric images (3Dorthoimage) (Figure 6). The current structure is a frame vault, characterized by two large and respectively transverse and longitudinal arches which divide the surface in nine squares and support thinner vaults, made of brick tiles $(3-5 \mathrm{~cm})$, widely used since the Sixteenth century.

The investigation of easily detectable extrados parts makes a deeper knowledge of such constructions possible: it allows a better interpretation of recurring situations, even more problematic to be detected. This interpretation, however, cannot be carried out without an accurate survey integrated by the thermography extensively used at the intrados surfaces.

The integration of the 3D model of the intrados (laser scans) with the orthoimage of the extrados and the thermal image (intrados) allowed to reconstruct the geometry of the whole mixed vaulted structure, made by assembling the 4 arches and the light thin vault $(\sim 3 \mathrm{~cm})$ (Figure 7):

a. the 4 arches can be considered the components of a 'skeleton', made by mean of the 2 main longitudinal arches (brick block used for the reinforced arches are textured in a vertical position on header), maybe the first elements built up in the sequence, with the 2 tie rods at the extrados embedded in the arches themselves giving stability and rigidity to the arches together with the frenelli; the 2 transversal arches complete the structure of the arches;

b. the vault itself is realized texturing the tile-brick block along the 
'curved shape' as described in the first part of the paper and here reconstructed from the scans: the vaults is not independent from the arches, in fact it has been gripped to the arches thanks to the interaction of some vertical brick block of the arches interweaved among the tiles in correspondence of the arches (Figure 8).
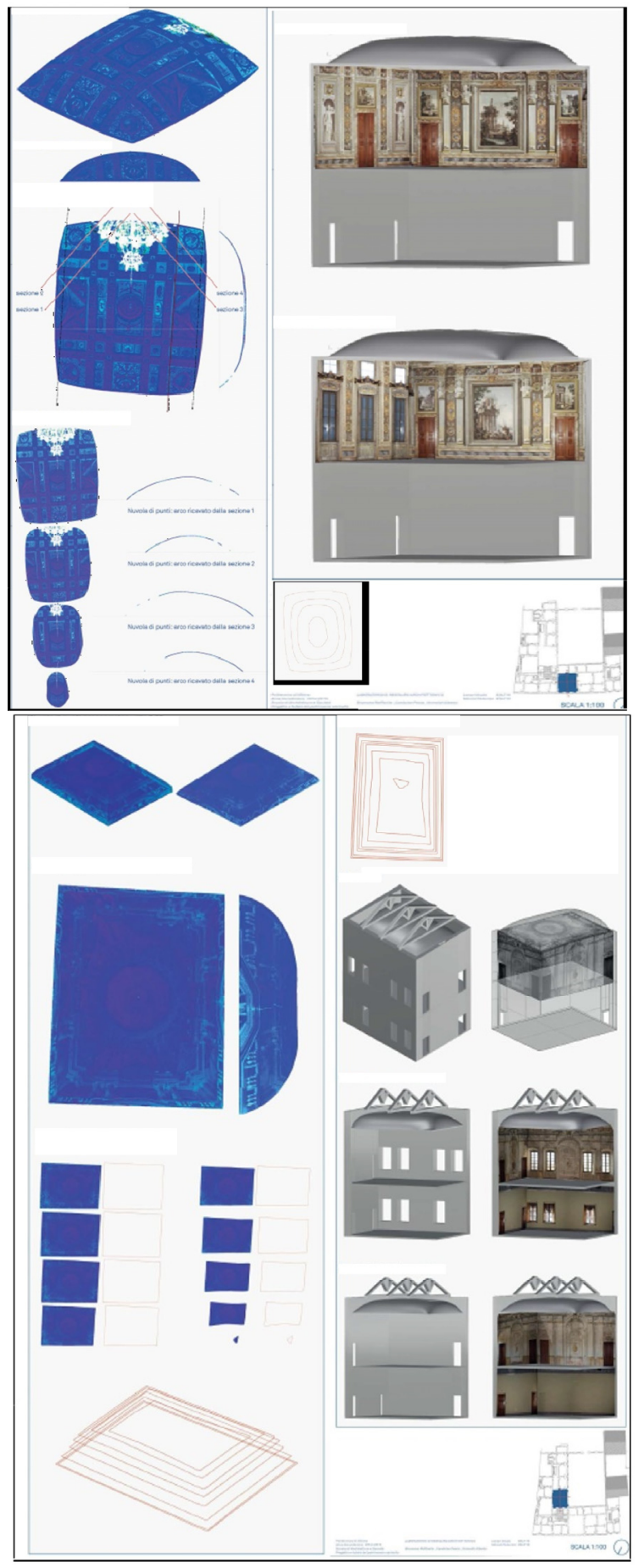

Figure 5. The registered laser-scans allow to obtain a sort of 'recognizable footprint' (blue) of the 2 vaults of the Manfredini Halls apparently similar, but very different as for the geometry highlighting different construction techniques: on the left the horizontal slices put in evidence the rounded shape of the vault, while on the right the typical rectangular cloister shape. The HBIM library of the 2 Halls allows to manage the different data derived from the surveying and modelling.
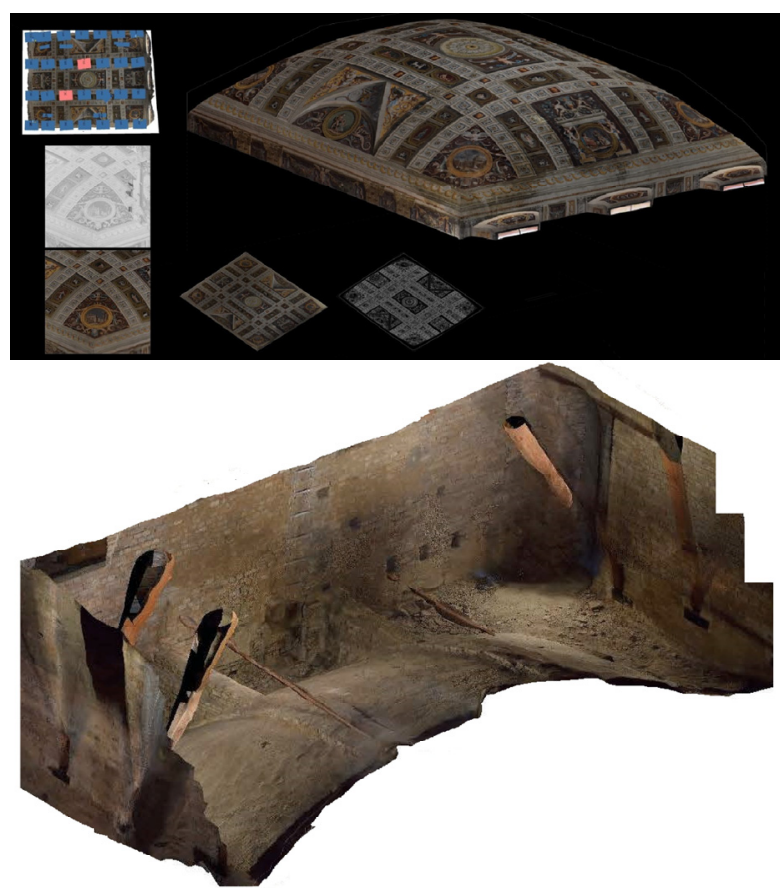

Figure6. The 3Dorthoimage of the intrados obtained on the laser-scans GCPs of the vault (upper); the 3D orthoimage of the extrados obtained by the photogrammetric image block

(bottom). (C GIcarus lab, PhD Riccardo Valente, and students courtesy).
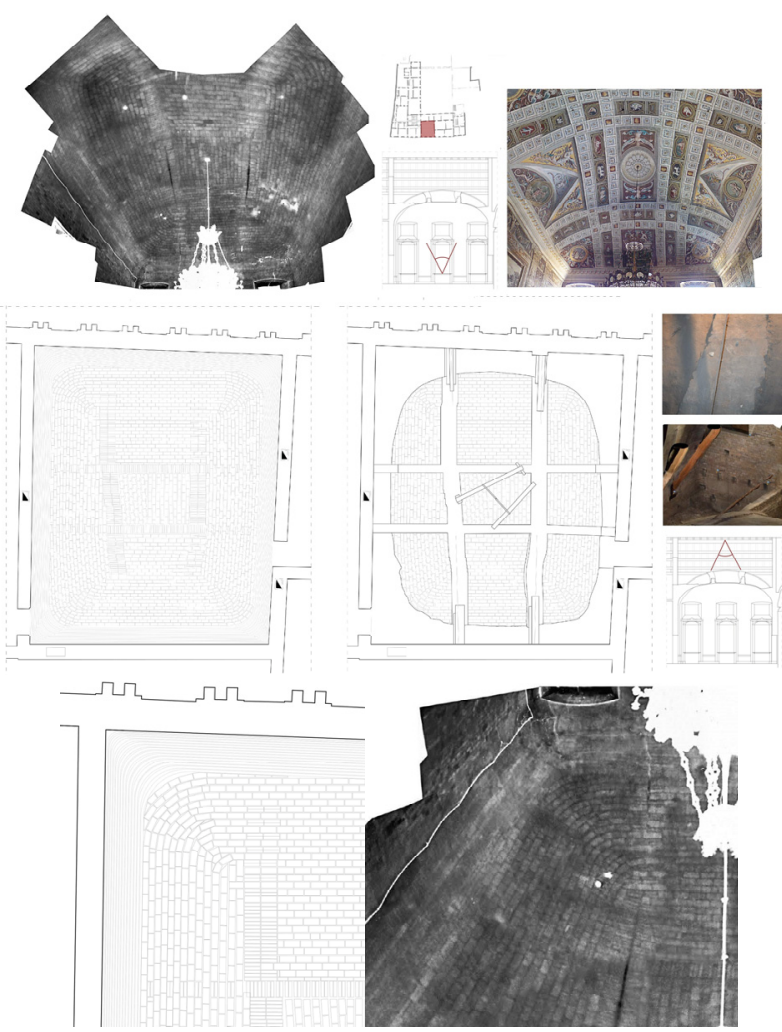

Figura 7. The information on the texturing have been read from the thermal mosaic (not-metric) of the intrados by mean of the grey tones thermal image mosaic (C DASTU, IRT images, Luca Valisi) and from the metric orthoimage of the estrados from the 3Dortoimage (C dABC GIcarus, Preservation lab, students courtesy) 




Figure 8 . The integration of the 2 orthoimages at the extrados and intrados with the thermal image (intrados) allowed to understand the detail of the integration of the interweaved structure obtained from the skeleton of the arches with the continuous thin structure of the vault. In fact, in correspondence of the arches are viewable both the brick block of the arches and the tiles of the vault hold on to the arches. The result is a perfect curved surface as highlighted by the laser scans (CdABC GIcarus, Preservation lab, students courtesy)

Following the intrados geometry, the HBIM reconstructed the position of the object elements of the tile brick block (thickness $4 \mathrm{~cm}$ ) used for the vault in order to diminish the weight, obtaining a sustainable very light structure compared with the dimensions of the covered hall. The modelled elements of all the components of the vault (arches and vaults) have been imported within the HBIM model in order to manage the abacus of the different elements.

A in folio cloister vault from the same period in courses parallel to the springers covers the loggia towards the courtyard, but the span is relatively limited $(3 \mathrm{~m})$ and the section is semi-circular. It is the thinnest wall overlooking the courtyard (three bricks thick, $45 \mathrm{~cm}$ ) which suggested lesser thickness of the vault.

The construction is lighter than the vaults of the interior wing, and stability is favoured by a larger rise. The larger height of the street-side façade corresponds to a higher volume of the attic area where the vaults have ample space.

\section{REMARKS}

In summary, it seems that the different constructive outlines used in the wing overlooking the road and the interior wing have been chosen as they best respond to the - differing -work conditions.

Two completely different construction sites could be hypothesised, with completely different master builders, in the two wings, which can be recognised by the different thicknesses (in folio brick, brick-on-soldier technique), but the various chronological hypotheses already discussed exclude a gap between the two of any more than twenty years. Numerous examples of contemporary in folio vaults can be found in the city - just think of those by Faustino Rodi in the Town Hall (Jean, 1998) and Palazzo Cattaneo built from 1788 (Grimoldi, 2005), but there are some that date even further back in Palazzo Ariguzzi Pallavicino (Grimoldi and Landi, 2012). Examples of the brick-on-soldier technique can be found in the vaults of the

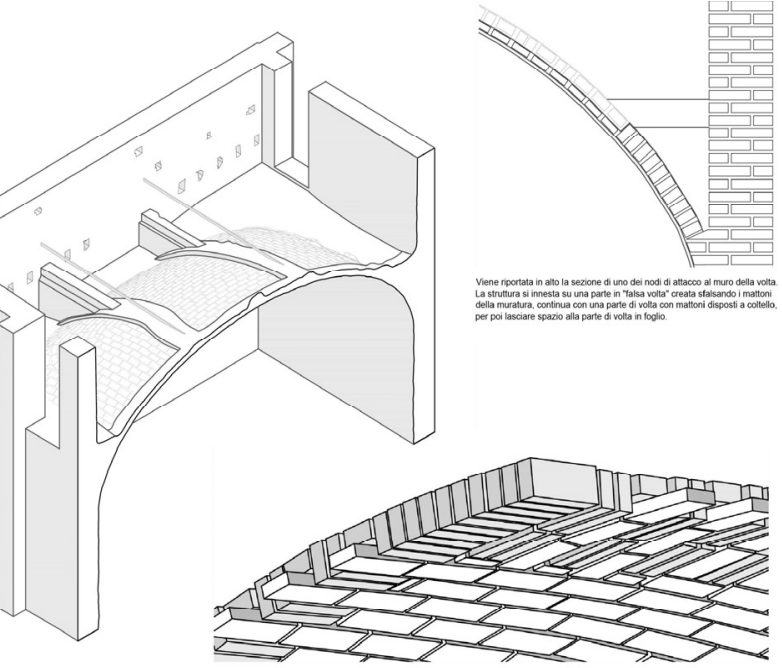

piano nobile of Palazzo Raimondi (between 1828 and 1836) and the vaults of the ground floor in the same building, hardly beyond the first half of the 17 th century.

The great variety of cases - as regards geometry and arrangement, but also deformation and crack pattern - analysed, in the same building, in the same period, in the same city, shows the poor foundation of any generalization, but the rapidity and reliability of results that guarantee detection techniques today - metric and quantitative - and thermography, essentially qualitative, should favour their adoption, and also substantially change the quality of the strengthening project.

\section{ACKNOWLEDGEMENTS}

The authors would like to thank at the students of the Preservation lab Course of the years 2015 and 2016, and particularly D. Attico, M. Mottadelli, E. Strano, A. Turrina, A. Greppi, C. Midali, C. Parolini and M. Pizzuti, G. Laneri, F. Moroni.

\section{REFERENCES}

AEC (CAN) BIM Protocol, 2014. Implementing Canadian BIM Standards for the Architectural, Engineering and Construction industry based on international collaboration.

AIA, 2015. The American Institute of Architects', BIM Forum, Level of Development (LOD) Specification.

Banfi F., 2016. Building Information Modelling - A Novel Parametric Modeling Approach Based on 3D Surveys of Historic Architecture. In: Digital Heritage. Progress in Cultural Heritage: Documentation, Preservation, and Protection, 6th International Conference, EuroMed 2016, Springer, pp. 116127

Barazzetti L., Banfi F., Brumana R., 2016. HBIM in the Cloud. In: Digital Heritage. Progress in Cultural Heritage: Documentation, Preservation, and Protection, 6th International Conference, EuroMed 2016, Springer, pp. 104-115. "Werner Weber Award".

Barazzetti, L., Banfi, F., Brumana R., Gusmeroli, G., Previtali, M., Schiantarelli, G., 2015b. Cloud-to-BIM-to-FEM: Structural simulation with accurate historic BIM from laser scans. In: Simulation Modeling Practice and Theory, vol. 57, pp. 71-87.

Barazzetti, L., Banfi, F., Brumana, R., Previtali, M., 2015a. Creation of Parametric BIM Objects from Point Clouds Using. In: The Photogrammetric Record, 30(152), p. 339-362. 
Brumana, R., Oreni, D., Cuca, B., Binda, L., Condoleo, P., Triggiani, M., 2014. Strategy for Integrated Surveying Techniques Finalized to Interpretive Models in a Byzantine Church, Mesopotam, Albania. In: International Journal of Architectural Heritage Conservation, Analysis, and Restoration, (8)6, 2014, pp.886-924.

Etlin, R.A., 2015. The strenght of vaults. In: Proceedings of the fifth international congress on construction history, June 2015, Construction history society of America, Chicago, Illinois, pp. 49-60.

Fai, S. \& Sydor, M., 2013. Building Information Modeling and the Documentation of Architectural Heritage: Between the 'Typical' and the 'Specific. In: Digital Heritage International Congress (DigitalHeritage). Marseilles, France, pp.731-734.

Fai, S., Rafeiro, J., 2014. Establishing an appropriate level of detail (LoD) for a building information model (BIM) -West Block, Parliament Hill, Ottawa, Canada. In: ISPRS Annals of the Photogrammetry, Remote Sensing and Spatial Information Sciences, 2(5), pp.123-130.

Forni, M., 1993. La cultura architettonica nella prima metà del Settecento: considerazioni ed ipotesi sulle relazioni con il quadro europeo. $\mathrm{PhD}$ thesis, Politecnico di Milano.

Gilly, D., 1797. Handbuch der Land-Bau-Kunst, vorzüglich in Rücksicht auf die Construction der Wohn- und WirthschaftsGebäude für angehende Cameral-Baumeister und Oeconomen. Berlin, Vieweg.

Grimoldi, A. and Landi, A. G., 2012. The spread of the XVIIth century vaults in Cremona. The case study of Magio Grasselli Palace. In: Jerzy Jasienko (Ed.). Proceedings of 8th International Conference on Structural Analysis of Historical Constuction. pp. 1136-1144.

Grimoldi, A., 2005. Ricerca storica e diagnosi del degrado statico nel patrimonio edilizio esistente. Il Palazzo Cattaneo a Cremona. In: Aveta A, Casiello S., La Regina F., Picone R. (Eds.), Restauro, e Consolidamento. Mancosu, Roma, pp. 216221.

Grimoldi, A., 2009. The "frame vaults" of North Italy between the sixteenth and the Eighteenth Century. In: third International Congress construction history. Cottbus 20-24/5/2009, Neunplus, Berlin, pp. 753-759.

Holzer, S.M., 2013. Statische Beurteilung historischer Tragwerke vol. I Mauerwerkskonstruktionen. Enrst \& Sohn, Berlin.

Jean, G., 1998. I lavori di Faustino Rodi nel Palazzo comunale di Cremona. In: Bollettino storico cremonese. pp.126-138.

Landi, A., 2011. Riforme edilizie in una dimora aristocratica cremonese: palazzo Magio-Grasselli. In: Landi A. (Ed.), Patrizi, notabili, costruzione della città. Palazzo MagioGrasselli a Cremona tra civitas e urbs. U. Allemandi, Torino, pp. 33-116.

NBS. 2016. National BIM Report. https://www.thenbs.com

Oreni, D., Brumana, R., Georgopoulos, A., Cuca B., 2013. HBIM for conservation and management of built heritage: towards a library of vaults and wooden bean floors. In:
Grussenmeyer, P. (Ed.), ISPRS Annals of Photogrammetry, Remote Sensing and Spatial Information Sciences, vol. II-5/W1. Copernicus Publications. pp. 215-221.

Palacios Gonzalo, J.C., 1990. Trazas y cortes de cantería en el Renacimiento español. Ministerio de cultura, Instituto de conservacion y restauracion de bienes culturales, Madrid.

Pérouse de Monclos, J.M. (Ed.), 1972. Architecture, vocabulaire, Ministère de la culture et de la communication, Inventaire général des monuments et des richesses artistiques de la France. Imp. Nationale, Paris.

Pérouse de Monclos, J.M., 1982. L'architecture à la francaise: XVI, XVII, XVIII siecles. Picard, Paris.

Piccoli, E., 1999. Volte composte nell'architettura piemontese del Settecento: le volte planteriane. In: PALLADIO, VII(23), pp.87-100.

Piccoli, E., 2001. Le strutture voltate nell'architettura civile a Torino, 1660-1720. In: Dardanello G. (Ed.), Sperimentare l'architettura. Guarini, Juvarra, Alfieri, Borra e Vittone. Fondazione Crt, Torino, pp. 38-96.

Piegl, L. A., Tiller, W., 1997. The NURBS book. Springer

Varagnoli C., 2009. La costruzione tradizionale in Abruzzo. Fonti materiali e tecniche costruttive dalla fine del Medioevo all'Ottocento. Gangemi, Roma, pp. 49-64.

Visioli, M., 2001. Palazzo Raimondi, nuove ricerche in occasione dei restauri alla facciata. M. Baroni Editore, Viareggio.

Volk, R., Stengel, J., Schultmann, F., 2014. Building Information Modeling (BIM) for existing buildings - Literature review and future needs. In: Automation in Construction, 38, pp 109-127.

Wendland, D., 2008. Lassaulx und der Gewölbebau mit selbsttragenden Mauerschichten: neumittelalterliche Architektur um 1825 - 1848. Imhof, Petersberg.

Wendland, D., 2014. Reverse Engineering und Experimentelle Archäologie - Forschungen zu Bau, Planungsprinzipien und Entwurfskriterien spätgotischer Zellengewölbe. In: Schröck K. und Wendland D. (Eds.), Traces of Making. Entwurfsprinzipien von spätgotischen Gewölben / Shape, Design, and Construction of Late Gothic Vaults, Michael Imhof Verlag, Petersberg, pp. $11-38$.

Willis, R., 1842. On the construction of the vaults of the middle ages. In: Transactions of the Royal Institute of British Architects, Vol. 1, Part 2, Longman, Brown, Green and Longmans, London, pp. 1-61. 